ISSN 0189-6016@2009

\title{
BIOCHEMICAL AND TOXICOLOGICAL STUDIES OF AQUEOUS EXTRACT OF SYZIGIUM AROMATICUM (L.) MERR. \& PERRY (MYRTACEAE) IN RODENTS
}

\author{
Agbaje E.O.* ${ }^{1}$, Adeneye A. A. ${ }^{2}$, Daramola A. O. ${ }^{3}$ \\ ${ }^{1}$ Department of Pharmacology, College of Medicine of the University of Lagos, Lagos, Nigeria, \\ ${ }^{2}$ Department of Pharmacology, Faculty of Basic Medical Sciences, Lagos State University, College of \\ Medicine, Ikeja, Lagos, Nigeria, ${ }^{3}$ Department of Morbid Anatomy, College of Medicine of the \\ University of Lagos, Lagos, Nigeria \\ *E-mail: agbajegoriite@yahoo.com
}

\begin{abstract}
The effects of long-term administration of boiled aqueous extract of Syzigium aromaticum (SYZ), commonly known as clove (which has been locally employed for treating gastrointestinal tract diseases and also used as food spices), on some biochemical indices, such as body weight, liver functions and blood parameters were studied in adult albino rats of both sexes. Selected doses of 300 and $700 \mathrm{mg} \mathrm{kg}^{-1}$ were given orally through cannular to groups of animals for a period of 90 days, while the control group received distilled water throughout the duration of study via the same route. Blood samples collected after therapy and assayed for activities of some liver enzymes recorded a significant $(\mathrm{p}<0.05)$ and prominent effect on ALP and AST. Measurement of haematological parameters also revealed significant effects $(\mathrm{p}<0.05 ; \mathrm{p}<0.001)$ on $\mathrm{Hb}, \mathrm{RBC}(\mathrm{p}<0.05), \mathrm{PCV}$ $(p<0.001)$, platelets $(p<0.001)$ and granulocytes $(p<0.001)$. An insignificant reduction was recorded for total WBC. The histopathological study conducted was in consonance with the results of the biochemical investigations that the aqueous extract of SYZ even at moderate doses, significantly affects body organs, their enzymes as well as the various functions. $\mathrm{LD}_{50}$ for both intraperitoneal and oral routes of SYZ were 263 and $2500 \mathrm{mg} \mathrm{kg}^{-1}$ respectively. The present work has revealed the toxicity of sub chronic administration of SYZ, which suggests that its prolonged usage must be avoided.
\end{abstract}

Key Words: Syzigium aromaticum, toxicity, biochemical parameters, haematological parameters, aqueous extract.

\section{Introduction}

Natural plant products have been used for therapeutic purposes since the time immemorial and their use is of a greater demand nowadays (Calixto, 2000). Majority of the users rely on herbal medicines for health care because the other treatment options available are more expensive and they are often thought to be more associated with serious side effects. Most of these plants have been ingested indiscriminately by many local populations for the management of various disease states without neither knowing how relief is brought about nor having adequate information on the safety/toxicity risks associated with their use. For proper enlightenment and guidance of the populace, especially users of these natural products, there is need for scientific documentation on the safety/toxicity profile of these acclaimed medicinal plants.

The indigenous medicinal plants in Nigeria form an important component of the natural wealth of the country and Syzigium aromaticum L. (family: Myrtaceae), formerly known as Eugenia caryophyllata,, commonly known as Clove, and is one of the most widely used plants in this environment for medicinal purposes. It is an evergreen tree in the Myrtle family and grows in warm climates but cultivated commercially in Tanzania, Sumatra, the Maluku (Molucca) Islands and South America (Bisset, 1994). The tree grows up to $20 \mathrm{~m}$ and has leathery leaves. Furthermore, the clove spice is the dried flower bud measuring between 12 to $22 \mathrm{~mm}$ in length, with 4 projecting calyx lobes folded to form a hood, which hides numerous stamens (Dalziel, 1937). 
Twenty-two compounds have been identified in the extracts of clove buds with eugenol and eugenyl acetate as the major aroma constituents (Bensky et al., 2004). Essential oils are obtained from the buds, stems and leaves (Lawless, 1995). The essential oil from clove is used as a topical application to relieve pain and promote healing in herbal medicine (Prashar et al., 2006). Antioxidant activity found comparable to that of the natural antioxidant, vitamin E was documented (Lee and Shibamoto, 2001). Eugenol was also reported to have strong acaricidal activity (Fichi et al., 2007), anthelmintic property (Balch and Balch, 2000) and antiinflammatory effect (Dip et al., 2004). Its antibacterial and anticarcinogenic effects were independently observed by Burt and Reinders (2003) and Dorai and Aggarwal (2004). Recently, Trongtokit et al., 2005 showed that clove oil is an effective mosquito repellent.

Clove oil had long been recognized as safe and used in foods, beverages and tooth pastes, but toxicities which could be life-threatening were reported much later (Lane et al., 1991; Brow et al., 1992; PTCL 2005; and Prashar et al., 2006). The systemic use of the essential oil has been restricted to three drops per day for an adult as excessive use can cause severe kidney damage (Bensky et al., 2004).

The dried bud of Syzigium aromaticum has a widespread use in this environment as a decoction macerated in water or occasionally lightly boiled in aqueous media for treating diverse ailments, especially, gastrointestinal disorders. Alternatively, it could be used as a concoction with other plants. The dearth of information on the toxicity profile of the aqueous preparation of the bud necessitated the present investigation of its acute and sub-chronic ingestion in animal model.

\section{Materials and Methods \\ Plant Materials and Preparation of Aqueous Extract}

Dried buds of $S Y Z$ were purchased from Mushin market in Lagos metropolis, Lagos State, Nigeria. Plant authentication and extract preparation procedures have been earlier documented (Agbaje, 2008).

\section{pH Determination of the Extract}

The extract $\mathrm{pH}$ was determined using a pH meter (Cole Parmer, Chicago, Illinois 60648), under the required standard conditions. The extract $\mathrm{pH}$ at $100 \mathrm{mg} \mathrm{ml}^{-1}$ was $4.6 \pm 0.04$

\section{Experimental Animals}

Healthy Swiss albino mice and Wistar rats of both sexes ranging between 15-20 g and 90-130 g obtained from the Laboratory Animal Centre of the College of Medicine were employed for the study. They were maintained under standard laboratory conditions all through the period of study and were fed on pelleted diet (Neimeth Nigeria Plc, Ikeja, Lagos State, Nigeria) and given tap water ad libitum. Animals were kept in well-ventilated house conditions (room temperature range: $27^{\circ} \mathrm{C}-30^{\circ} \mathrm{C}$; photoperiod: $12 \mathrm{~h}$ natural light and $12 \mathrm{~h}$ dark; humidity: 50-55\%). Experimental procedures were according to the Guidelines for Animal Experimentation as approved by the international, national and institutional guidelines for the Use and Care of Experimental Animals.

\section{Acute Toxicity Test}

A total of thirty overnight fasted mice $(n=5)$ were separately used for evaluating acute toxicity of $S Y Z$. Doses of 100-520 mg kg-1 were administered intraperitoneally (i.p) and larger doses of 500-5000 mg kg-1 by oral gavage to separate groups of animals. Control group received $10 \mathrm{ml} \mathrm{kg}^{-1}$ distilled water via the same routes. The animals were observed for respiratory, GIT, CNS symptoms, behavioural patterns and mortality. The LD $_{50}$ was determined by graphical method (Miller and Tainter, 1944).

\section{Sub-Chronic Toxicity Studies}

Twenty four rats were randomly divided into three groups with Groups I and II having six animals each, while Group III had twelve rats. Prior to the commencement of investigation, the animals were fasted overnight but had access to drinking water at will. Group I served as control and received $10 \mathrm{ml} \mathrm{kg}^{-1} \mathrm{water}$ orally. Group II received 300 and Group III $700 \mathrm{mg} \mathrm{kg}^{-1}$. All the animals were kept on the scheduled treatment for 90 days. Group III was divided into A and B of six rats each. While the first half was sacrificed at the termination of drug therapy, the remaining animals were left for extra two weeks to assess the possible reversibility of the 
toxicity of SYZ. Body weights of the animals were monitored throughout the period of study and the mean values recorded.

\section{Blood Collection and Bioassays}

Blood samples for bioassays were obtained from rats by cardiac puncture under diethyl ether anaesthesia after $48 \mathrm{~h}$ of termination of treatment. Blood samples for biochemical assays (liver and renal function tests) were collected into sterile plain bottles while those for haematological assay were collected into EDTA-treated sample bottles. Haematological parameters-packed cell volume, total and differential white blood cell and platelet counts were analyzed using Advia ${ }^{\mathrm{TM}} 60$ closed tube (CT) Automated haematology System (Bayer Corporation, Tarrytown, New York, U.S.A).

The serum activities of liver enzymes alkaline phosphatase (ALP), was estimated by method of Sigma (1987), while those of Aspartate aminotransferase (AST) and alanine aminotransferase (ALT) were estimated by colorimetric method (Sigma Diagnostic, 1985). Serum sodium and potassium were estimated by using clinical flame photometer at $410{ }^{\circ} \mathrm{C}$ while urea was estimated by modified diacetylmonoamine method (Marsh, 1965). Estimation of serum creatinine was done by the Jaffe's reaction method (Biod and Sirota, 1948). The serum total protein was estimated by Biuret method (Treitz, 1970), while that of albumin was determined by bromocresol green (Lowry et al, 1957). The total bilirubin and the conjugated bilirubin were determined by Jendrassik-Grof method (Spencer and Price, 1977). The serum cholesterol was determined by Lierbermann quantitative test (1958).

\section{Histopathological studies of selected vital Organs}

Post-mortem examination was carried out on all the animals sacrificed as described above, and vital organs - liver, kidney, lungs, stomach, spleen, heart and brain were selected for histopathological study. After blood rinsing in normal saline, sections were taken from each selected vital organ. The tissues were fixed in $10 \%$ formo-saline, dehydrated with $100 \%$ ethanol solution and embedded in paraffin. It was then processed into 4-5 $\mu \mathrm{m}$ thick sections stained with haematoxylin-eosin and observed under a microscope.

\section{Statistical Analysis}

Results were presented as mean \pm S.E.M of six observations for each group. Statistical analysis was made using two-ways analysis of variance using SYSAT 10.6 statistical software programme. The values were considered significantly different when the p-value was less than 0.05 .

\section{Results \\ Acute toxicity study}

It was observed that the animals treated with $S Y Z$ were generally normal. Daily cage-side observations did not reveal any physical changes in the skin, fur, eyes, respiratory system and general behavioural patterns. The only toxic manifestation was abdominal writhing, however, a few animals died before the end of the study. $\mathrm{LD}_{50}$ was interpolated from the probit vs log-dose curve as $263.0 \mathrm{mg} \mathrm{kg}^{-1}$ (i.p) and $2500.0 \mathrm{mg} \mathrm{kg}^{-1}$ (oral).

\section{Effect of 90-days of oral treatment with SYZ on body weights of treated rats}

Body weight of all the SYZ treated animals increased in a dose dependent fashion with reference to the initial weight (Figure 1). When compared with the control group however, the mean weight gained in the treated rats was significantly lower $(\mathrm{p}<0.05)$, (Figure 2$)$.

\section{Effect of extract on weight of body organs}

The effect of $S Y Z$ on weights of some vital body organs in rats showed no significant difference in the organ weight in both treated and control groups except that of stomach $(\mathrm{p}<0.05)$ (Figure 3$)$. 


\section{Haematological responses of rats to 90 days of oral treatment with $S Y Z$}

As shown in Table 1, repeated oral administration of $S Y Z$ to the treated rats caused significant effects on RBC ( $p<0.05), \mathrm{Hb}(\mathrm{p}<0.05 ; \mathrm{p}<0.001), \mathrm{PCV}(\mathrm{p}<0.001)$, and platelets $(\mathrm{p}<0.001)$, while there was no significant effects on the total white blood count (TWBC), lymphocyte, and neutrophil counts ( $>0.05)$ (Table 2).

\section{Effects of the extract on serum electrolytes, urea and creatinine}

SYZ caused a significant reduction $(\mathrm{p}<0.001)$ in the serum electrolytes as shown in Table 3 , while inducing a significant increase $(\mathrm{p}<0.05)$ in the serum urea. Both changes occurred in the group assayed, two weeks after cessation of therapy.

Table 1: Effect of $S Y Z$ on the haematological parameters

$$
\text { DOSES }\left(\mathrm{mg} \mathrm{kg}^{-1}\right)
$$

$\begin{array}{llll}\begin{array}{l}\text { Blood } \\ \text { Parameter }\end{array} & 0 & 300 & 700\end{array}$

\begin{tabular}{|c|c|c|c|c|}
\hline $\operatorname{PCV}(\%)$ & $43.57 \pm 2.36$ & $46.72 \pm 0.27$ & $49.85 \pm 0.42 * * *,+$ & $39.77 \pm 1.06^{*}$ \\
\hline $\mathrm{Hb}(\mathrm{g} / \mathrm{dl})$ & $13.77 \pm 0.52$ & $14.40 \pm 0.24^{*,+}$ & $15.40 \pm 0.18^{* * *,+}$ & $12.36 \pm 0.24^{*,-}$ \\
\hline $\mathrm{MCH}(\mathrm{pg})$ & $18.73 \pm 0.35$ & $18.30 \pm 0.26$ & $18.35 \pm 0.11$ & $18.13 \pm 0.15$ \\
\hline $\mathrm{MCHC}(\mathrm{g} / \mathrm{dl})$ & $31.63 \pm 0.38$ & $31.03 \pm 0.22$ & $30.90 \pm 0.09$ & $30.87 \pm 0.26$ \\
\hline MCV (fl) & $59.73 \pm 0.80$ & $58.74 \pm 0.58$ & $59.50 \pm 0.54$ & $58.73 \pm 0.82$ \\
\hline \multicolumn{2}{|c|}{$\mathrm{RBC}\left(\times 10^{6} / \mu \mathrm{L}\right) 7.45 \pm 0.38$} & $7.81 \pm 0.17$ & $8.36 \pm 0.16^{*,+}$ & $6.77 \pm 0.09$ \\
\hline \multicolumn{3}{|c|}{ PLT $\left(\times 10^{3} / \mu \mathrm{L}\right) 535.17 \pm 80.29539 \pm 102.78$} & $868.00 \pm 50.54 * * *,+$ & $607.00 \pm 29.10$ \\
\hline
\end{tabular}

$*,-, * * *,--$ represent significant decreases at $\mathrm{p}<0.05$ and $\mathrm{p}<0.001$ respectively when compared with control values;

$*,+, * * *,+$ represent significant rise at $\mathrm{p}<0.05$ and $\mathrm{p}<0.001$, respectively, when compared with the control values.

Table 2: Effect of $S Y Z$ on total and differential WBC

\section{DOSES (mg kg $\left.{ }^{-1}\right)$}

$\begin{array}{lll}0 & 300 & 700\end{array}$

Parameter

\begin{tabular}{|c|c|c|c|c|}
\hline $\mathrm{TWBC}\left(\times 10^{3} / \mu \mathrm{L}\right)$ & $14.92 \pm 1.73$ & $15.13 \pm 2.33$ & $13.20 \pm 1.88$ & $9.60 \pm 0.89$ \\
\hline Lymph. (\%) & $9.13 \pm 1.39$ & $9.93 \pm 3.02$ & $8.05 \pm 1.19$ & $6.37 \pm 0.83$ \\
\hline Gran. (\%) & $2.13 \pm 0.60$ & $2.02 \pm 0.47$ & $2.20 \pm 0.31$ & $0.60 \pm 0.04 * * *,-$ \\
\hline Neutr. (\%) & $2.47 \pm 0.32$ & $1.87 \pm 0.24$ & $2.95 \pm 0.38$ & $2.37 \pm 0.20$ \\
\hline
\end{tabular}

$* * *,-$ represents a significant decrease at $\mathrm{p}<0.001$ when compared to the control values. 
Table 3: Effect of SYZ on serum electrolytes, urea and creatinine in rats

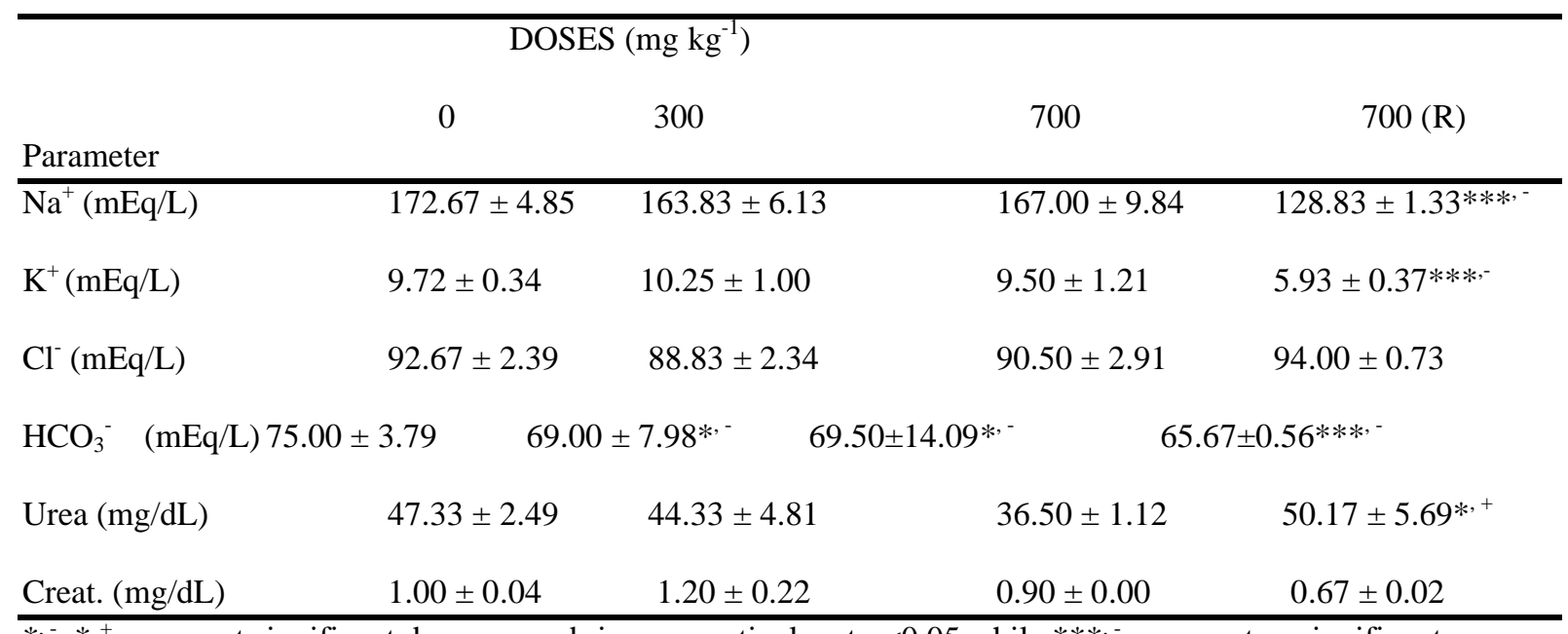

${ }^{*,-},{ }^{*},{ }^{+}$represent significant decrease and rise, respectively, at $\mathrm{p}<0.05$ while ${ }^{* * *},-$ represents a significant decrease at $\mathrm{p}<0.001$.

Table 4: Effect of $S Y Z$ on serum total proteins, cholesterol and conjugated bilirubin in rats

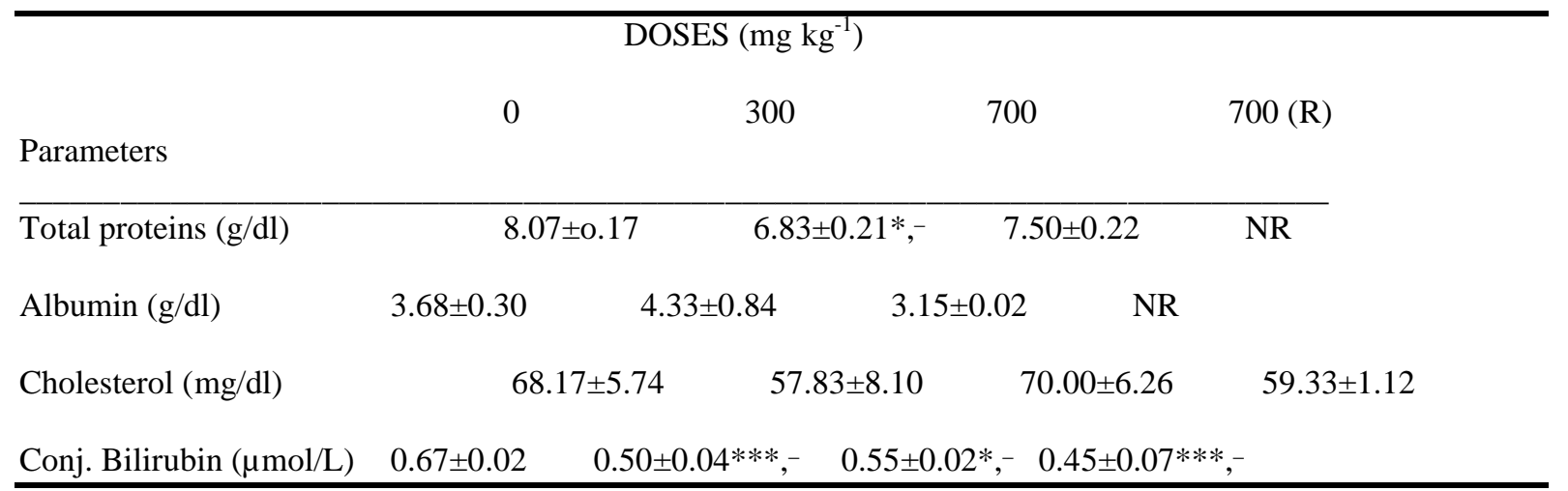

$\mathrm{NR}=$ not recorded; ${ }^{*,-}$ represents a significant decrease at $\mathrm{p}<0.05$ while ${ }^{* * *,-}$ represents a significant decrease at $\mathrm{p}<0.001$.

Table 5: Effects of $S Y Z$ on liver enzymes in rats

\begin{tabular}{|c|c|c|c|c|}
\hline \multicolumn{5}{|c|}{ DOSES $\left(\mathrm{mg} \mathrm{kg}^{-1}\right)$} \\
\hline enzyme & 0 & 300 & 700 & $700(\mathrm{R})$ \\
\hline$\overline{\mathrm{ALP}}(\mathrm{IU} / \mathrm{L})$ & $0.35 \pm 0.02$ & $0.15 \pm 0.02 * * *$ & $0.15 \pm 0.02 * * *,-$ & $0.10 \pm 0.00 * * *$ \\
\hline ALT (IU/L) & $56.00 \pm 2.25$ & $51.00 \pm 11.74$ & $51.00 \pm 2.68$ & $60.33 \pm 12.53$ \\
\hline AST (IU/L) & $62.33 \pm 12.72$ & $62.17 \pm 28.86$ & $93.50 \pm 0.22 * * *,+$ & $58.33 \pm 13.88^{* * *},-$ \\
\hline
\end{tabular}


Table 6: Histological changes observed in the liver, spleen, brain, lungs, heart, testes and stomach of rats treated with SYZ for 90 days.

\begin{tabular}{|c|c|c|c|c|c|c|c|c|c|}
\hline Organs & Histological changes & & & Grp 1 & & Grp II & & Grp IIIA & Grp IIIB \\
\hline \multirow[t]{2}{*}{ Liver } & 1. Steatosis & & & - & & ++ & & + & \\
\hline & $\begin{array}{l}\text { 2. Perivenular, periportal and } \\
\text { sinusoidal inflammatory infiltrates }\end{array}$ & & - & & + & & ++ & & ++ \\
\hline Spleen & Normal & & - & & - & & - & & - \\
\hline \multirow[t]{2}{*}{ Brain } & 1. Oedema & & & + & & + & & +++ & +++ \\
\hline & 2. Congestion & & & & & - & & +++ & +++ \\
\hline Lungs & Patchy atelectasis & + & + & & + & & + & & \\
\hline Heart & Normal & - & & - & & - & & - & \\
\hline Kidney & Tubular necrosis & - & - & & ++ & ++ & & & \\
\hline Testes & Normal & - & & - & & - & & - & \\
\hline Stomach Gastritis & - & + & & & ++ & & ++ & & \\
\hline
\end{tabular}

Key: - = no change $+=$ mild; $++=$ moderate $;+++=$ severe

Grp I = control; Grp II = low dose; Grp IIIA = high dose; Grp IIIB = reversibility test

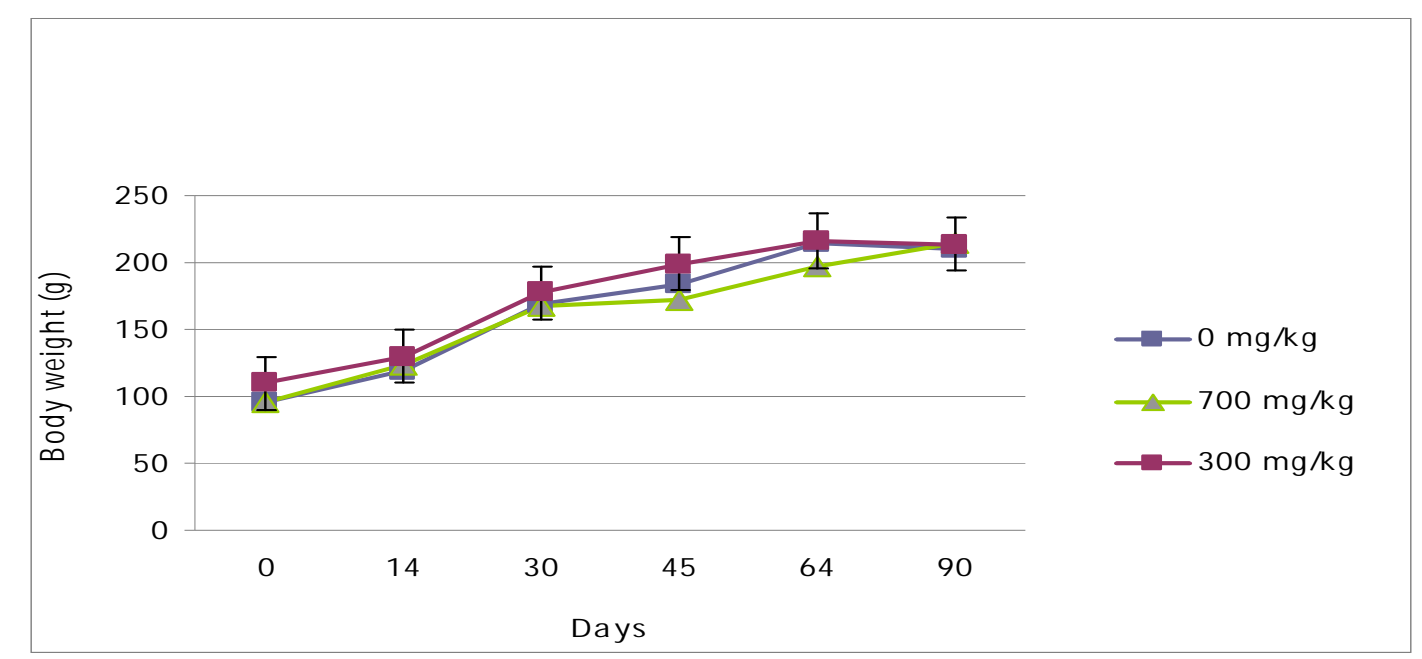

Figure 1: Effect of Oral SYZ on body weight changes during 90 days treatment. Data represent mean \pm SEM of 6 animals. 


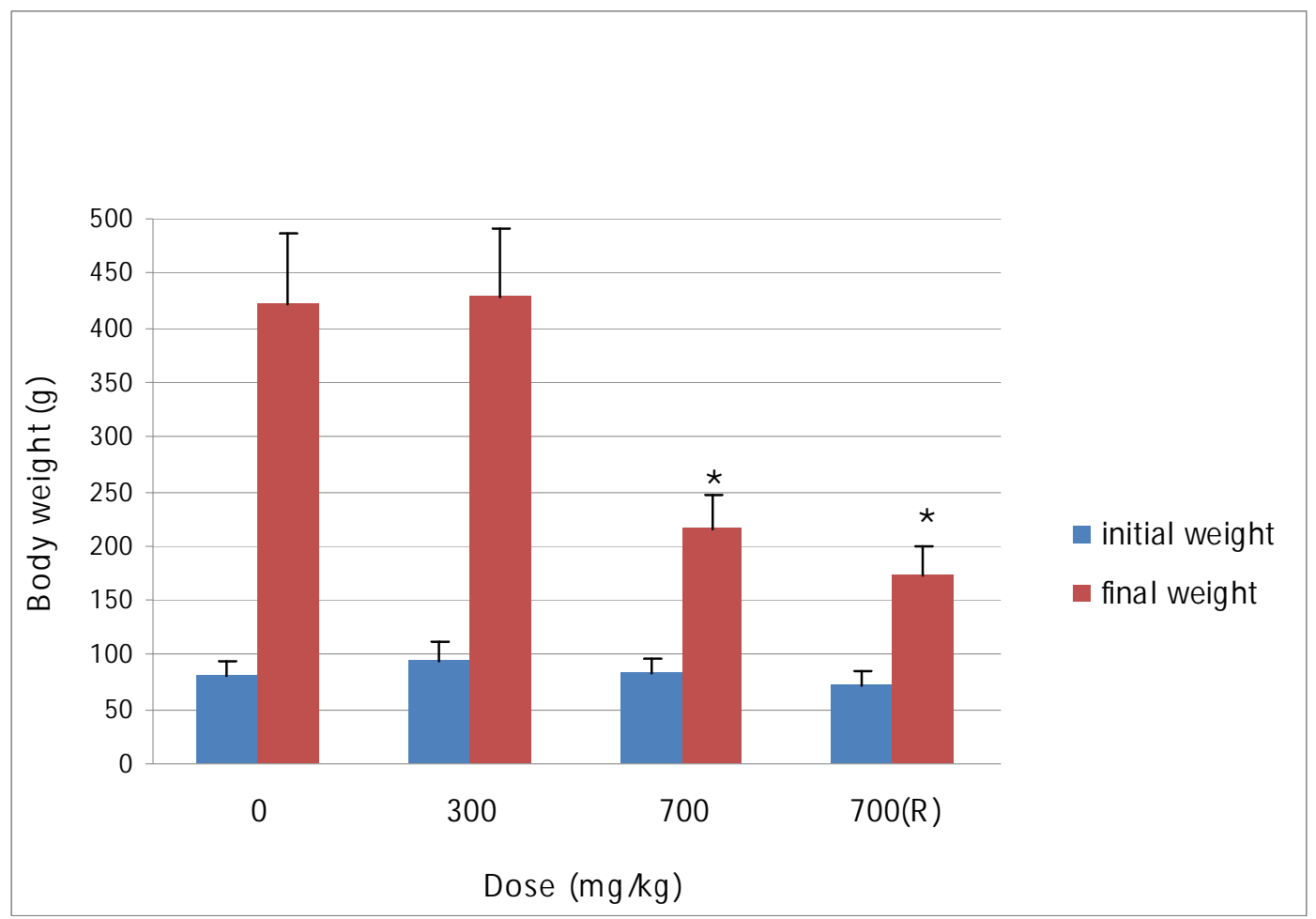

Figures 2: Effect of Oral SYZ on weight gain in rats after 90 days treatment. Data represent mean \pm SEM of 6 animals. *Values compared with control significant at $\mathrm{p}<0.05$.

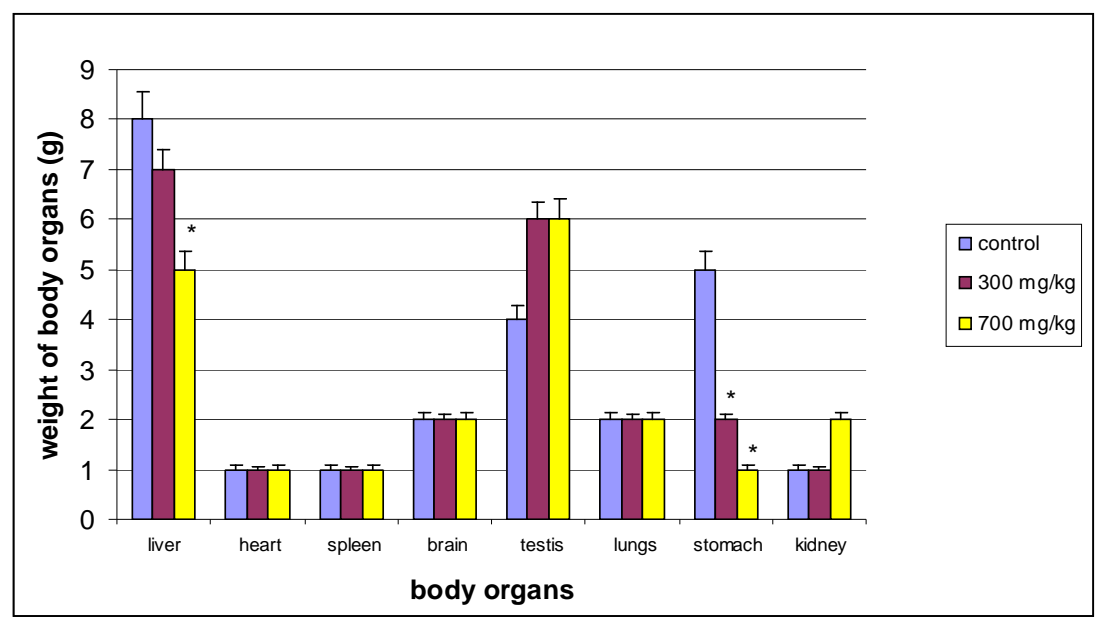

Figures 3: Effect of Oral SYZ on Organ weights. Data represent mean \pm SEM of 6 animals. *Values compared with control significant at $\mathrm{p}<0.05$. 


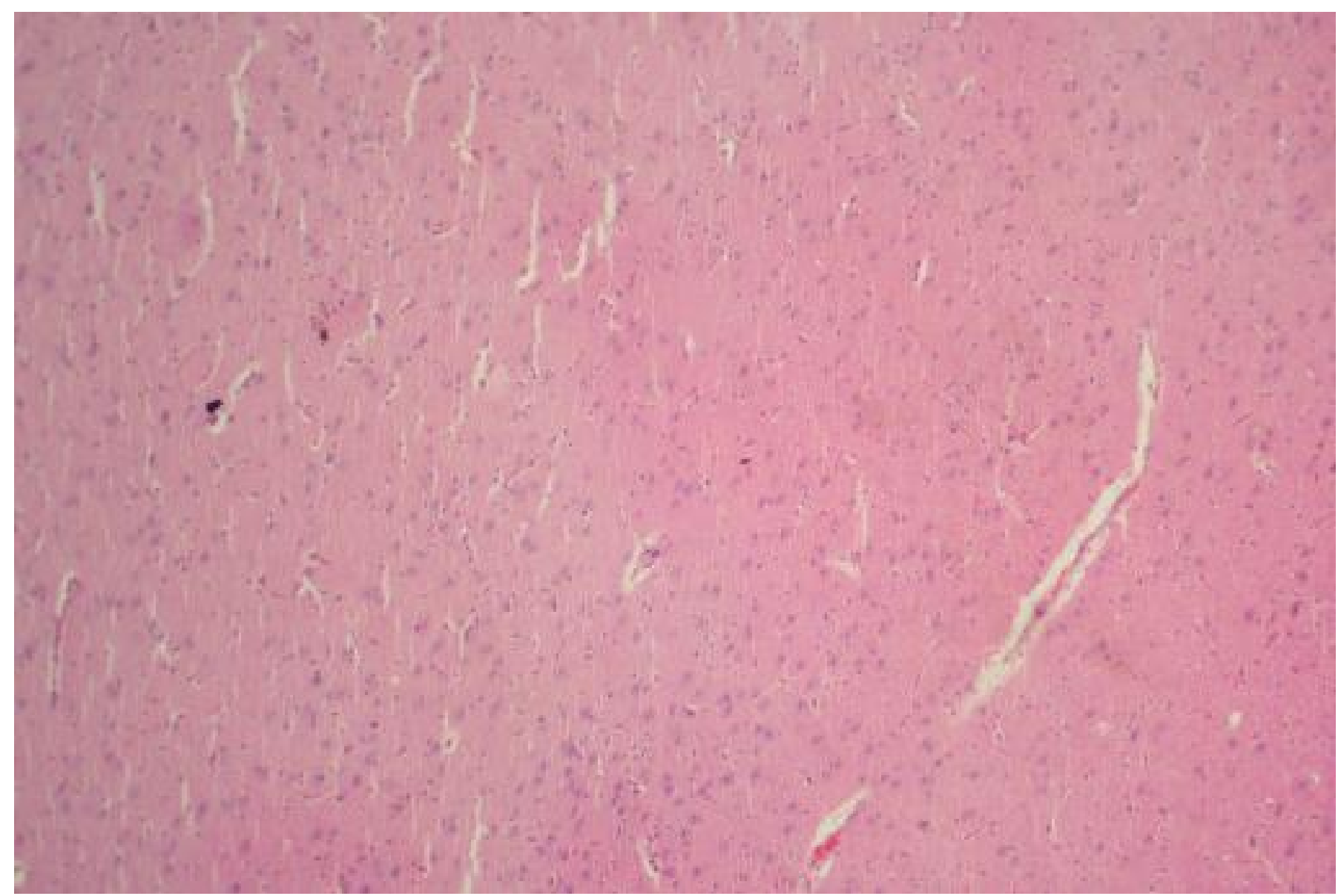

Figure 4: Brain Group II $\times 100$ : Showing mild oedema characterized by widening of space around blood vessels (thin arrow), reduced intensity of staining and friability of brain substance (thick arrow).

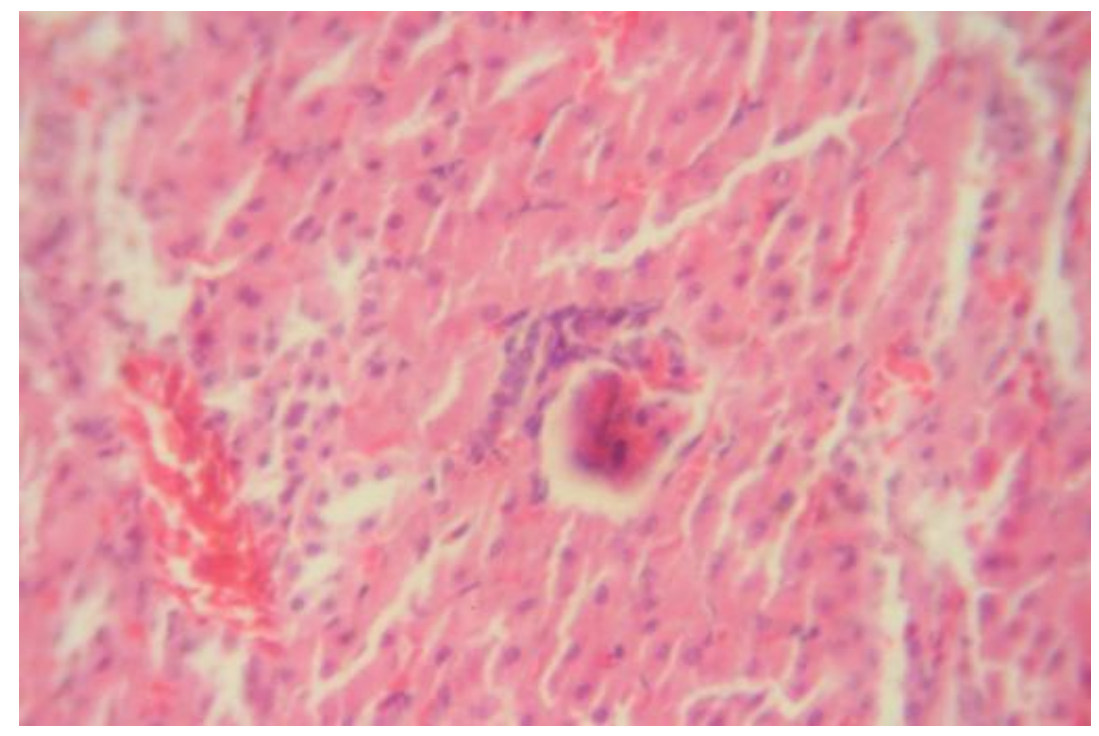

Figure 5: Kidney Group III $\times 400$ : Tubular necrosis (arrows). 


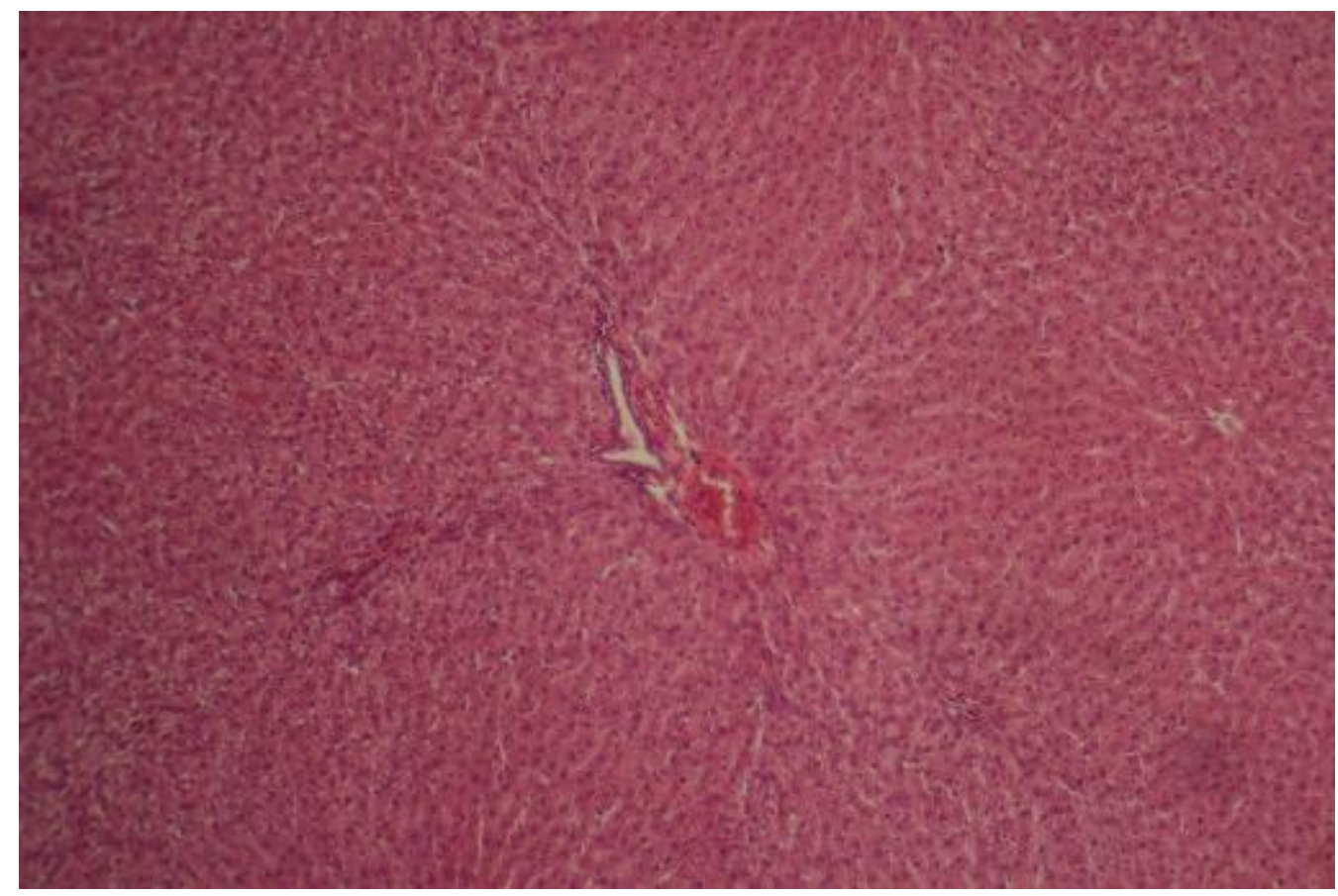

Figure 6: Liver Group I ×100: Showing normal morphology

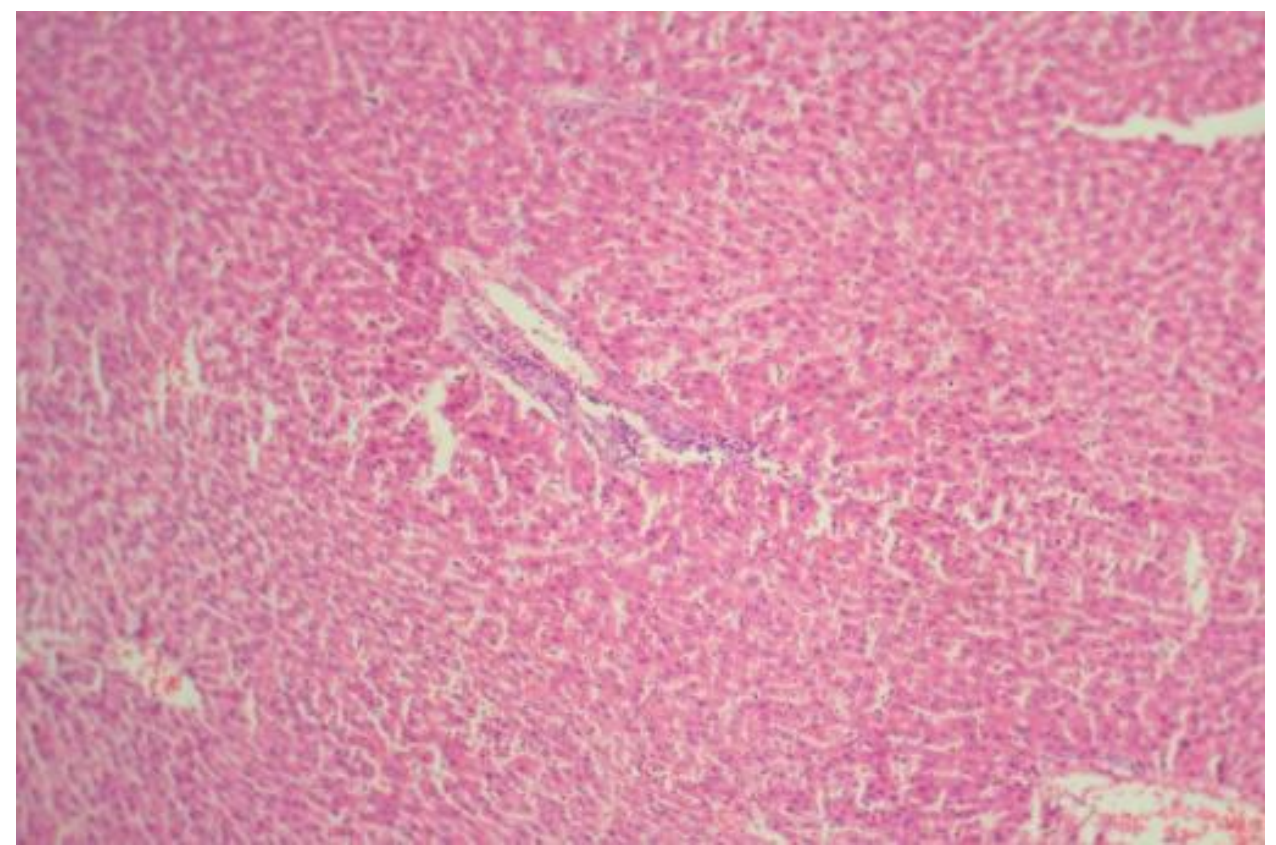

Figure 7: Liver Group IIIA ×40: Showing perivenular, periportal and sinusoidal inflammatory infiltrates 


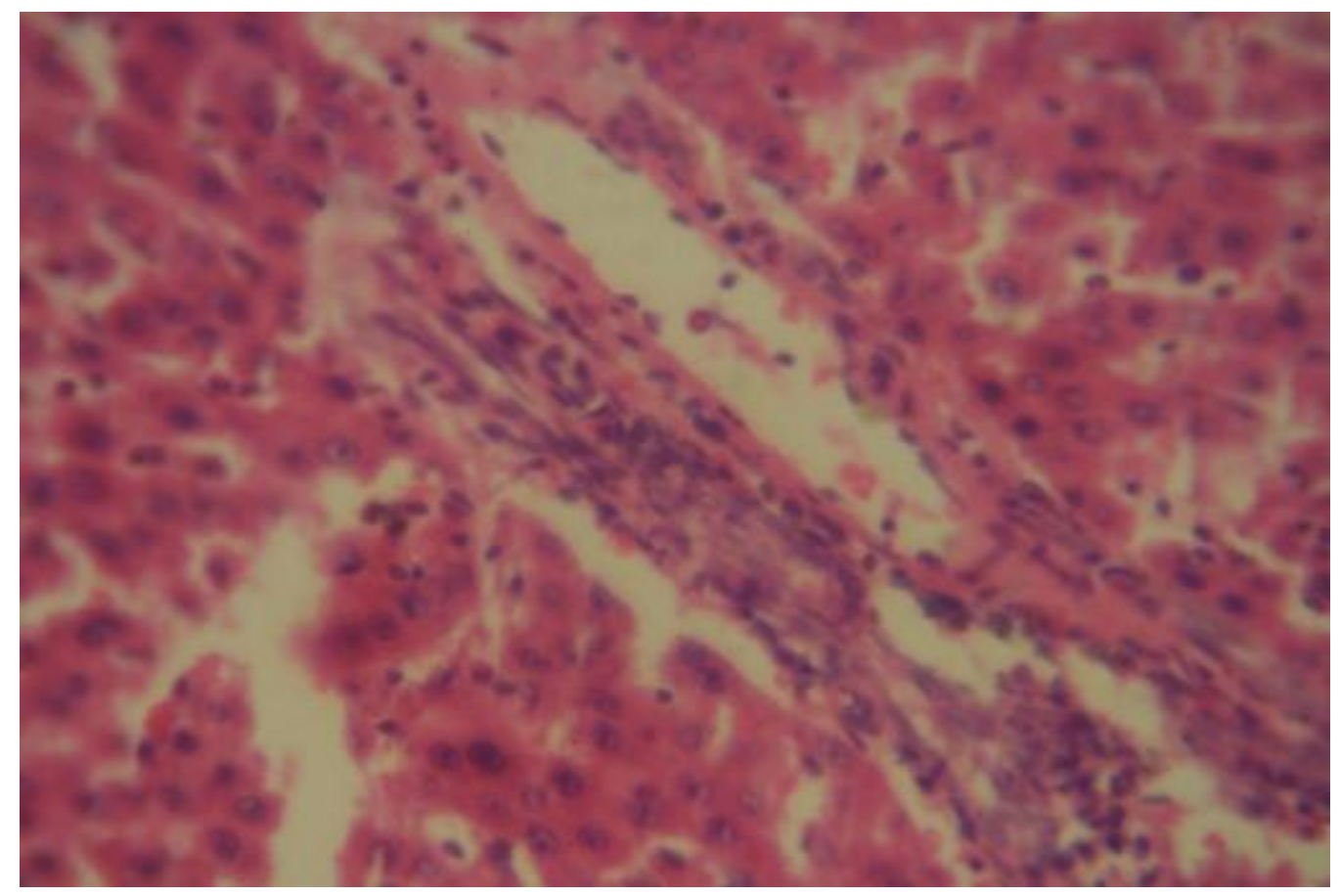

Figure 8: Liver Group IIIB $\times 400$ : Showing periportal inflammation

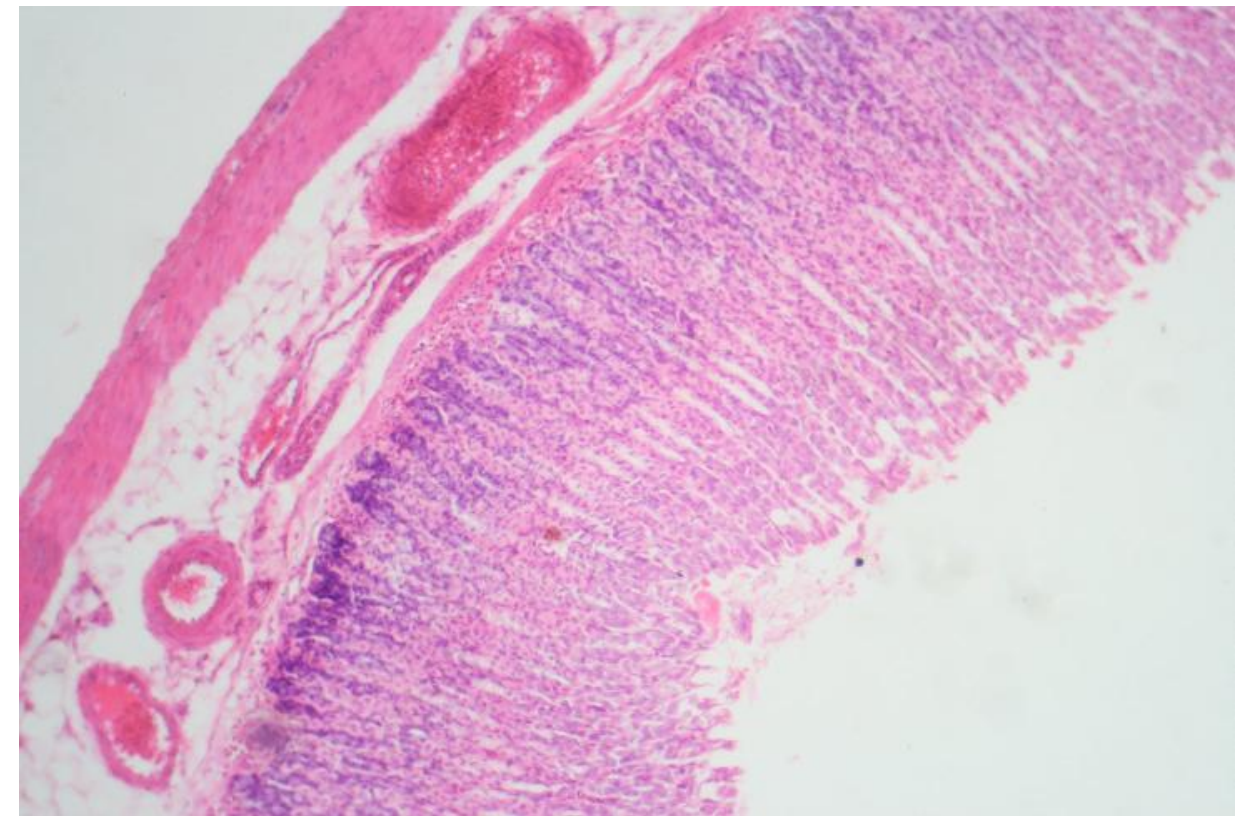

Figure 9: Stomach Group I ×40: Showing normal morphology 


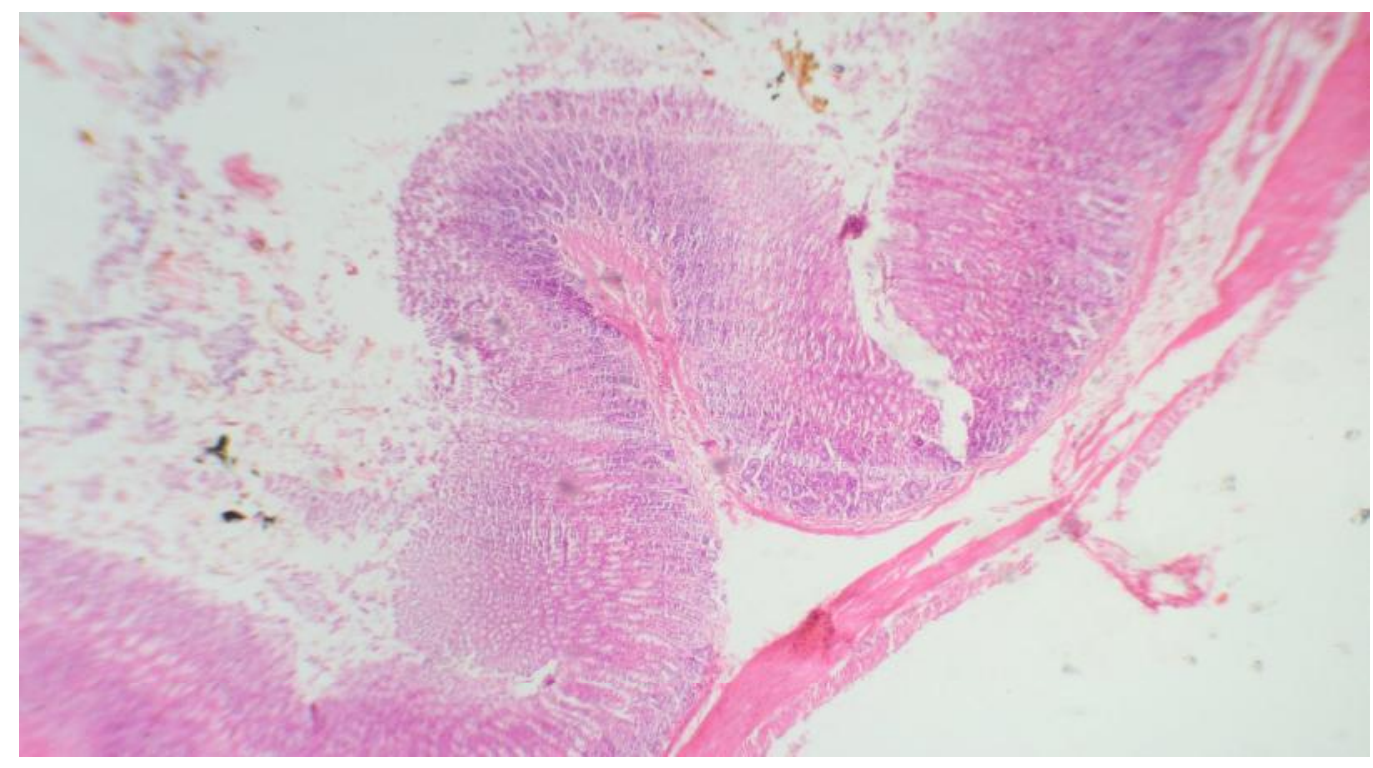

Figure 10: Stomach Group IIIA ×40: Showing gastritis and tissue necrosis

\section{Effects of $S Y Z$ on the serum proteins, cholesterol, bilirubin and liver enzymes}

The data obtained showed no significant effect on cholesterol and albumin, while a significant decrease in value was recorded for bilirubin $(\mathrm{p}<0.05 ; \mathrm{p}<0.001)$ (Table 4$)$. On the other hand, $S Y Z$ exerted a prominent effect on both ALP and AST ( $p<0.001)$, while inducing no significant difference on ALT ( $>0.05)$ (Table 5).

\section{Histopathological effect of repeated oral administration of SYZ on selected vital organs}

The spleen, heart, and testes did not reveal any morphological changes on gross and histological examinations. On the other hand, severe and irreversible toxicity was observed on the liver, brain, kidney and stomach (Table 6).

\section{Discussion}

The result of acute oral toxicity recorded the $\mathrm{LD}_{50}$ of $S Y Z$ as $2500 \mathrm{mg} \mathrm{kg}^{-1}$ which showed its relative safety as classified by the Organization for Economic Cooperation and Development (OECD, Paris-France) (Walum, 1998). On the other hand, i.p route recorded $\mathrm{LD}_{50}$ as $263 \mathrm{mg} \mathrm{kg}^{-1}$. It could be conjectured that the herbal drug undergoes the first pass effect when administered orally. $\mathrm{LD}_{50}$ is not a biological constant because many variables such as animals' species and strain, age, gender, diet, bedding, ambient temperature, caging conditions and time of the day can all affect its value; hence there are considerable uncertainties in extrapolating $\mathrm{LD}_{50}$ value obtained for a species to other species. Consequently, $\mathrm{LD}_{50}$ test provides at best, only a ballpark estimate of human lethality (Zbinden and Flury-Roversi, 1981; Oduola et al., 2007).

All the treated rats recorded much less body weight than the control group (Figure 2) and the percentage weight gain during the study period in Groups I, II, III A and B respectively are $428.1 \%, 350.0 \%, 160.6 \%$, and $139.0 \%$. Inability of the SYZ treated groups to gain as much weight as the water treated group might be due either to the effect of the extract on the internal organs (Figures 3 and 10), or to the general discomfort which led to a low feeding rate in the treated rats (Oyewole et al., 2007). Administration of a chemical compound may bring about significant changes in the structure, function, metabolic transformation and concentration of biomolecules, enzymes and even metabolic pathways. These alterations, which may be rapid or slow may lead to different biochemical mechanisms producing similar pathological, clinical and laboratory findings (Murray et al., 
2000). Assessment of haematological parameters can be used to determine the extent of deleterious effect of foreign compound including plant extract on the blood. It can also be used to explain blood relating functions of chemical compound/plant extract. Such laboratory investigations have been reported to be highly sensitive, accurate, and reliable and it remains the bedrock of ethical and rational research, disease diagnosis, prevention and treatment (Okonkwo et al, 2004; Yakubu et al., 2007).

The extract significantly increased $\mathrm{RBC}, \mathrm{Hb}$ and $\mathrm{PCV}$, which was followed by a significant fall two weeks after cessation of therapy (Table 1). SYZ has been found to contain flavonoids (Agbaje, 2008), which are free radical scavengers. It is therefore possible that these components compete with $\mathrm{Hb}$ in $\mathrm{RBC}$ for oxygen, resulting in hypoxia, which then stimulates synthesis and RBC production. It is also possible that the end product of $S Y Z$ metabolism in the body stimulates the kidney directly to cause formation and secretion of erythropoietin, which is the humoral regulator of RBC production (Sanchez-Elsner et al., 2004). Kobzik and Schoen (1994), and Imoru et al. (2006) reported that interstitial pulmonary fibrosis is often associated with tissue anoxia, which in turn stimulates increased formation of ertthropoietin, a glycoprotein which stimulates increased RBC production. It is therefore very likely that $S Y Z$ contains erythropoietin-like principle(s), which is responsible for the high $\mathrm{RBC}$ and PCV values recorded in this study.

The calculated blood indices - MCV, MCH and MCHC have a particular importance in anaemia diagnosis in most animals (Coles, 1986). The non-significant effect on these indices relating to RBC suggests that there was no effect on the average size of RBC and also on the haemoglobin weight per RBC. This implies that the aqueous plant extract did not possess any potential of inducing anaemia throughout the period of treatment.

On the other hand, SYZ extract produced a non-significant reduction of TWBC at the higher dose level, the trend which was sustained even after cessation of therapy. Similar reductions in granulocytes were also recorded. It is projected that the extract contains some bioactive agents that could cause destruction or impair production of WBC. It has been reported that granulocyte-macrophage colony stimulating factor, macrophage colony stimulating factor, interleukins IL-2, IL-4 and IL-5 regulate the proliferation, differentiation and maturation of committed stem cells responsible for the production of white blood cells (Guyton and Hall, 2000; Ganong, 2001). It may be that some components of the extract reduced the production of these regulatory factors or interfered with the sensitivity of the committed stem cells (responsible for the production of white blood cells) to these factors (Adebayo et al., 2005) Thus, administration of the extract may predispose to infection as it manifests immunosuppressive tendency.

The significant elevation of platelets $(\mathrm{p}<0.001)$, is also an indication that $S Y Z$ at a very high dose could predispose its users to hypercoagulable state, hence, spontaneous intravascular clotting and thrombo-embolism.

The Liver is one of the most important organs in the body and is responsible for breaking down all 'poisons' that enter the body and liver diseases could be mild or severe. Liver function tests conducted through blood assays give information about the state of the liver, describing its functionality, e.g. albumin, cellular integrity, e.g. transaminases and its link with the biliary tract e.g. gamma-glutamyl transferase and alkaline phosphatase. ALT is the enzyme produced within the cells of the liver, recording increases in conditions where liver cells have been inflamed or undergone cell death. As the cells are damaged, the ALT leaks into the bloodstream leading to a rise in the serum levels. It is the most sensitive marker for liver cell damage. The present study showed a significant increase only in the levels of AST, a state which can be associated with cell necrosis of many tissues (Adedapo et al., 2004). The latter observation could be substantiated by the results of the histopathological study, which revealed the toxicity of $S Y Z$ on most of the body organ which could have consequently produced cell death. Toxicity could be attributed to the different secondary metabolites such as saponins, anthraquinones, tannins, cardiac glycosides and flavonoids present in SYZ (Agbaje, 2008). A significant decrease in total protein level was recorded in group II animals that received $300 \mathrm{mg} \mathrm{kg}^{-1} \mathrm{SYZ}$ (Table 4). The fall in total protein may be due to poor nutrition, or malabsorption. Furthermore, the effect of $S Y Z$ recorded on blood electrolytes showed that the herbal preparation significantly affects kidney function (Table 3). The renal biochemical alterations were corroborated by the histopathological changes of tubular necrosis (Figure 5).

In conclusion, although SYZ has been reported by several workers to possess medicinal properties, this study however has shown that its indiscriminate and long-term use could be hazardous to body organs and it must therefore be ingested with caution.

\section{References}

1. Adebayo J.O., Adesokan A.A., Olatunji L.A., Buoro D.O., and Soladoye A.O. (2005). Effect of ethanolic extract of Bougainvillea spectabilis leaves on haematological and serum lipid variables in rats. Biokemistri 17 (1): 45-50. 
2. Adedapo A.A., Abatan M.O. and Olorunsogo O.O. (2004). Toxic effects of some plants in the genus Euphorbia on haematological and biochemical parameters of rats. Veterinarski Arhiv. 74(1): 53-62.

3. Agbaje E.O. (2008). Gastrointestinal effects of Syzigium aromaticum (L). Merr. \& Perry (Myrtaceae) in Animal model. Nig. Qt. J. Hosp. Med. 18 (3): 137-141.

4. Balch P. and Balch J. (2000). Prescription for Nutritional Healing, $3^{\text {rd }}$ ed. Garden City Park, N.Y. Avery. ISBN 158330771.

5. Bensky D.S., Clavey S. and Stoger E.(2004). Chinese Herbal Medicine: Materia Medica. Seattle, W.A: Eastland Press. ISBN 0939616424.

6. Biod T. and Sirota B. (1948). In: Watson, A., et al. (Eds.), Practical Clinical Biochemistry, $4^{\text {th }}$ ed. Prentice-Hall of India Private Ltd., New Delhi, India, pp. 142-145.

7. Bisset N. (1994). Herbal Drugs and Phytopharmaceuticals. Stuttgart, Germany, CRC Press, 130-131.

8. Brow S.A., Biggerstaff J. and Savidge G.F. (1992).Disseminated intravascular coagulation and hepatocellular necrosis due to clove oil. Blood Coagul. Fibrinolysis 3:665-668.

9. Burt S.A. and Reinders R.D. (2003). Natural products and nutritional supplements. Appl. Microb. 36(3): $162-7$.

10. Calixto J.B. (2000). Efficacy, Safety, Quality control, marketing and regulatory guidelines for herbal medicines (Phytotherapeutic agents). Braz. J. Med. \& Biol Res. 33 (2): 179-189.

11. Coles E.H. (1986). "Veterinary Clinical Pathology." W.B. Saunders, Philadelphia, U.S.A. pp. 10-42.

12. Dalziel J.M. (1937). The Useful Plants of West Tropical Africa. Crown Agents for the Colonies, London.

13. Dip E.C., Pereira N.A. and Fernandes P.D. (2004). Ability of Eugenol to reduce tongue edema induced by Dieffenbachia picta schott in mice. Toxicon. 43: 729-735.

14. Dorai T. and Aggarwal B.B. (2004). Role of chemopreventive agents in cancer therapy. Cancer Lett. 215: 129-140.

15. Fichi G., Flamini G., Giovanelli F., Otranto D. and Perrucci S. (2007). Efficacy of an essential oil of Eugenia caryophyllata against Psoroptes cuniculi. Exp. Parasitol. 115 (2): 168-172.

16. Ganong W.F. (2001). Review of Medical Physiology. $20^{\text {th }}$ Edition. Lange Medical Books. McGraw Hill Companies Inc., New York. Pp 500-515.

17. Guyton A.C., and Hall J.E., (2000). A Textbook on Medical Physiology. $10^{\text {th }}$ Edition. W.B. Saunders Company, Philadelphia. Pp. 382-401.

18. Imoru, J.O., Eno A.E., Unoh F.B., Nkanu, E.E., Ofem. O.E. and Ibu J.O. (2006).Haematopoietic Agent(s) in the crude extract from the leaves of Viscum album (Mustletoe). Nig. J. Hlth. Biom. Sc. 4 (2): 139-145.

19. Kobzik L. and Schoen F.J. (1994). The Lung. In: Cotran R.S., Kumar V., Robbins S.L. (Eds.): Robbins Pathologic Basis of Disease. $5^{\text {th }}$ ed. W.B. Saunders Co., Philadelphia, U.S.A., pp. 673-734.

20. Lane B.W., Ellenhorn M.J., Hulbert T.V., McCarron M, (1991). Clove oil ingestion in an infant, Hum. Exp. Toxicol. 10 (4): 291-294.

21. Lawless J. (1995). The Illustrated Encyclopedia of Essential oils. Rockport, MA: Element. ISBN 1852306610

22. Lee K.G. and Shibamoto T. (2001). Antioxidant property of aroma extract isolated from clove bud (Syzigium aromaticum (L). Merr. Et Perry). Food Chem. 74: 443-448.

23. Liebermann L.L. (1958). A method for the estimation of serum cholesterol. Clin. Chem. 2: 26-30.

24. Lowry O.H., Rosebrough N.J., Farr L. and Randall R.J. (1957). Protein measurement with Folin phenol reagent. J. Biol. Chem. 193: 265.

25. Marsh W.H. (1965). Automated and manual direct methods for the determination of blood urea. Clinical Chemistry 2: 624-625.

26. Miller L.C. and Tainter M.L. (1944). Estimation of the $\mathrm{LD}_{50}$ and its error by means of logarithmic probit graph paper. Proc. Sci. Expt. Biol. Med. 24: 839-840.

27. Murray R.K., Granner P.A., Mayer P.A., and Rodwell V.W. (2000). Harper's Biochemistry. $20^{\text {th }}$ edition. McGraw-Hill, pp. 594-602.

28. Oduola T., Adeniyi F.A.A., Ogunyemi E.O., Bello I.S., Idowu T.O., and Subair H.G. (2007). Toxicity studies on an unipe Carica papaya aqueous extract: biochemical and haematological effects in wistar albino rats. J. Med. Plant Res. 1 (1): 001-004

29. Okonkwo J.E., Iyadi K.C., and Effiong C.O. 2004). Effect of chronic administration of haematological parameters of rats. Nig. J. Physiol. Sc. 19 (1-2):10-13.

30. Oyewole I.O., Mogaji Z.J., Awoyinka O.A. (2007). Biochemical and Toxicological studies of aqueous extract of Tithonia diversifolia (Hemsl.) leaves in Wistar albino rats. J. Med. Plants Res. 1(2): 030-033.

31. Prashar A., Locke I.C. and Evans C.S. (2006). Cytotoxicity of clove (Syzigium aromaticum) oil and its major components to human skin cells. Cell Prolif. 39: 241-248.

32. Physical and Theoretical Chemistry Laboratory at Oxford (PTLC). 2005. Safety data for clove oil.Physical and Theoretical Chemistry Laboratory at Oxford. Retrieved April 6, 2008. 
33. Sanchez-Elsner T., Ramirez J.R., Rodriguez-Sanz F., Varela E., Bernabew C. and Botella L.M. (2004). A cross talk between hypoxia and TGF-beta orchestrates erythropoietin gene regulation through SPI and smads. J. Mol. Biol. 36 (1): 9-24.

34. Spencer K. and Price C.P. (1977). Chemical analysis of bilirubin in biological fluids. Annals Clinical Biochemistry 14: 105-115.

35. Sigma Diagnostic, (1985). Transaminase (ALT/GPT) and (AST/GOT) Procedure No. 505.

36. Sigma Diagnostic, (1987). ALP Optimized Alkaline Phosphatase. Procedure No. DG 1245.

37. Treitz N.W. (1970). Fundamentals of Clinical Chemistry with Clinical Correlation. W.B. Sanders, Philadelphia, pp. 280-284.

38. Trongtokit Y.Y., Rongsriyan N., Komalamisra N. and Apiwathnasom L. (2005). Comparative repellency of 38 essential oils against mosquito bites. Phytother Res. 19(4): 303-9.

39. Walum E. (1998). Acute oral toxicity. Environ. Health Perspect. 106: 497-503.

40. Yakubu M.T., Akanji M.A. and Oladiji A.T. (2007). Hematological evaluation in male albino rats following chronic administration of aqueous extract of Fadogia agretis stem. PHCOG MAG ISSN 09731296, pp. 34-38.

41. Zbinden G., and Flury-Rovers M. (1981). Significance of the $\mathrm{LD}_{50}$ test for toxicological evaluation of chemical substances. Arch. Toxicol. 49 (1): 99-103. 